\title{
Characterization of Nitrogen and Sulfur Compounds in Hydrocracking Feedstocks by Fourier Transform lon Cyclotron Mass Spectrometry
}

\author{
A.A. Al-Haiii, H. Muller and O.R. Koseoglu \\ Research \& Development Center, Saudi Aramco, PO Box 62, 31311 Dhahran, Kingdom of Saudi Arabia \\ e-mail: adnan.haji@aramco.com
}

Résumé - Caractérisation par spectrométrie de masse par résonance cyclotronique ionique à transformée de Fourier des composés azotés et soufrés dans les charges d'alimentation d'hydrocraquage - Une caractérisation poussée de deux charges d'alimentation en unités d'hydrocraquage lourdes, le gasoil lourd sous vide (Heavy Vacuum Gas Oil; HVGO) et le pétrole démétallisé (De-Metallized Oil; DMO), dérivées toutes deux de pétrole brut Arabian Light, a été réalisée par spectrométrie de masse par résonance cyclotronique ionique à transformée de Fourier à haute résolution (Fourier Transform Ion Cyclotron Resonance Mass Spectrometry; FT-ICR MS) afin d'obtenir des données approfondies sur leurs caractéristiques d'aromaticité et leur teneur en hétéroatomes, c'est-àdire en composés azotés et soufrés. Pour obtenir des données chimiquement utilisables, chaque signal massique individuel des spectres de masse à haute résolution a été relié à sa composition élémentaire sous-jacente, à l'équivalent de doubles liaisons pertinent (propriétés aromatiques) et au nombre de carbones. Le motif de distribution des espèces $\mathrm{N}$ et $\mathrm{S}$ du DMO est différent de celui du VGO. Le DMO contient des espèces aromatiques plus lourdes et plus condensées que le HVGO. Des espèces comportant jusqu'à trois atomes de soufre et deux atomes d'azote par molécule ont été trouvées dans chacune des deux charges d'alimentation. L'azote se trouve dans des structures pyrrole et pyridine dans les deux charges d'alimentation qui comprennent en outre de nombreuses espèces mono-, bi- et tri-sulfurées ainsi que des acridines et des carbazoles contenant de 1 à 3 atomes de soufre supplémentaires dans la même molécule.

\footnotetext{
Abstract - Characterization of Nitrogen and Sulfur Compounds in Hydrocracking Feedstocks by Fourier Transform Ion Cyclotron Mass Spectrometry - Advanced characterization of two heavy hydrocracking unit feedstocks, Heavy Vacuum Gas Oil (HVGO) and De-Metallized Oil (DMO), both derived from Arabian Light crude oil, was performed using High Resolution Fourier Transform Ion Cyclotron Resonance Mass Spectrometry (FT-ICR MS) to gain in-depth information on their aromaticity characteristics and heteroatom content, i.e., sulfur-and nitrogen-compounds. In order to obtain chemically utilizable information, each individual mass signal in the high resolution mass spectra was linked to its underlying elemental composition, the relevant double bond equivalent (aromatic properties), and carbon number. The DMO differs from the VGO in the $\mathrm{N}$-, and S-species distribution patterns. The DMO contains heavier and more condensed aromatic species than the HVGO. Species with up to three sulfur-and up to two nitrogen-atoms per molecule were found in both feedstocks. Nitrogen is present in both feedstocks in pyrrole- and pyridine-structures. Besides, numerous mono-, di-, and trisulfur species and acridines and carbazoles that contain 1 to 3 additional sulfur atoms in the same molecule were found in both feedstocks.
} 


\section{INTRODUCTION}

While specifications on transportation fuels tighten, the world's demand for crude oil is continuously increasing [1]. Moreover, supply of heavy and sour crude oil increases whereas the availability of light and sweet crude oils continues to decline [2,3] (Fig. 1, [4]).

Driven by environmental concerns, tighter sulfur specifications are mandated by current and pending legislation in the main consuming markets, e.g., $15 \mathrm{ppm}$ for transportation fuels in the USA [5] or $10 \mathrm{ppm}$ in the EU [6]. In addition, high sulfur levels in crude oil impact the refined products and increase the demand for more efficient downstream processes. Therefore, desulfurization is a widely used process in the refining of crude oil fractions (naphtha, gas oil, vacuum gas oil, etc.) to ultimately reduce emissions from combustion engines. Hydrocracking is also a major process in the refining industry for the conversion of vacuum gas oils to produce higher yields of high quality mid distillates to meet the current and future market demands.

There is a strong interest today in the processing of low value refractory feedstocks in order to improve the refining process economics. The feedstock's refractory nature has been described by several bulk properties including final boiling point, Micro Carbon Residue (MCR) content, total sulfur, and total nitrogen contents. The composition of feedstock is an important parameter impacting the process conditions (i.e., temperature, pressure, catalyst type and volume), but a detailed knowledge of the hydrocracking feedstock is

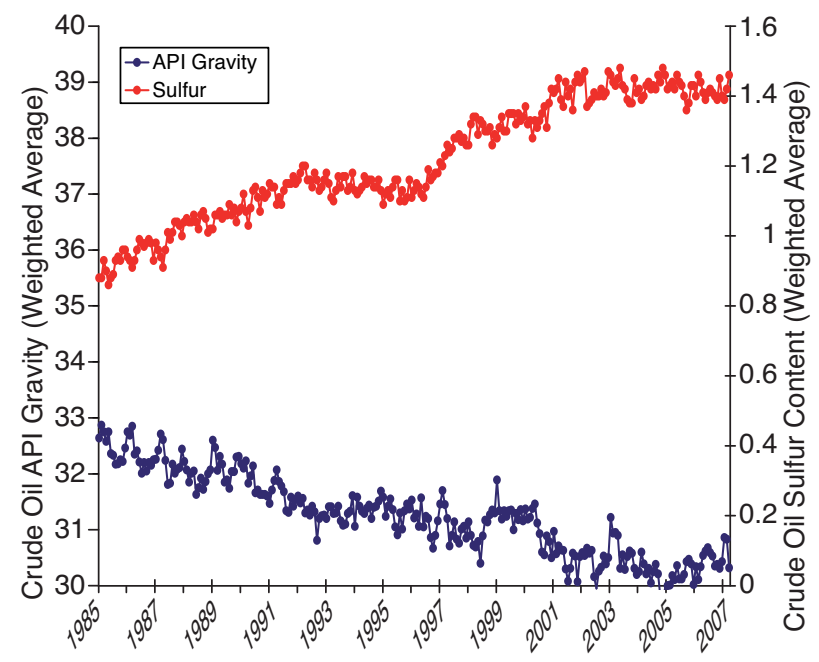

Figure 1

Sulfur content and API gravity for crude oil input to U.S. refineries from 1985 to 2007 [4]. more useful in optimizing the operational parameters for achieving desired optimum product specifications.

Numerous analytical tools have been employed for a detailed characterization of petroleum feedstocks. Among these, gas chromatography (GC) with sulfur specific detectors is routinely applied $[7,8]$. Unfortunately, due to the limitation by analyte volatility, analysis by GC is restricted to the hydrocarbon fractions boiling below $370^{\circ} \mathrm{C}$. Moreover, the complexity of crude oil and its heavy distillates exceed the peak capacity of any single-stage separation method [10].

Ultrahigh resolution Fourier Transform Ion Cyclotron Resonance (FT-ICR) Mass Spectrometry is rising recently as a powerful technique for the analysis of heavy petroleum fractions and whole crude oils [10-12]. Particularly, two ionization modes have been successfully employed for the analysis of sulfur aromatic and polar petroleum components: Electrospray Ionization (ESI) and Atmospheric Pressure Photoionization (APPI) [13, 14].

This study was initiated to carryout detailed characterization of hydrocracking unit feedstock components which will in turn help to understand the catalyst deactivation and optimize the hydrocracking process. We have analyzed heteroatom-containing and aromatic compounds of Heavy Vacuum Gas Oil (HVGO) and De-Metallized Oil (DMO) using FT-ICR MS.

The feedstocks are processed in a hydrocracking unit that is designed for 29000 Barrel Per Standard Day (BPSD) of fresh feedstock with 8000 BPSD of the unconverted, recycled oil. The unit processes a blend of VGO and DMO from a butane solvent deasphalting unit. There are two trains of equal capacity; each train has four reactors with a common fractionator. The two-stage series flow unit utilizes first-stage hydrocracking catalysts in the first two reactors and a zeolitic second-stage hydrocracking catalyst in the last two reactors. To prevent a $\mathrm{H}_{2} \mathrm{~S} /$ olefin recombination reaction, the process also utilizes a post treatment catalyst at the bottom of the last reactor. The unit is designed to be operated in recycle mode of operation with recycle to the first stage (direct recycle) and/or to the vacuum column (indirect recycle). The latter recycle was designed to alleviate heavy poly-nuclear aromatics (HPNA) buildup problem by rejecting them in the solvent deasphalting step.

The feedstock fractions were characterized by high temperature simulated distillation (Fig. 2). The hydrocracking unit feedstocks are not sharp cuts but have larger overlaps at the initial and final boiling points.

The DMO is processed to increase conversion in the refinery at the cost of hydrocracking process performance, product yields and quality. Figure 3 illustrates the reactivity of feedstocks from experiments conducted in a $100 \mathrm{cc}$ reactor pilot plant with a stacked bed catalysts configuration, where the first-stage hydrocracking catalyst was loaded at the top and zeolitic second-stage hydrocracking catalyst was loaded 


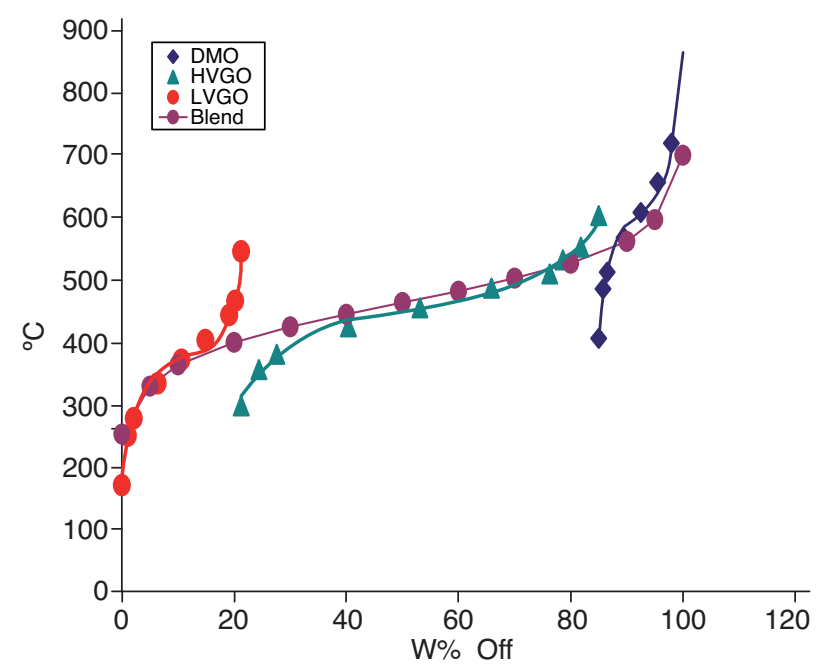

Figure 2

Distillation characteristics of the De-Metallized Oil (DMO) and Heavy Vacuum Gas Oil (HVGO).

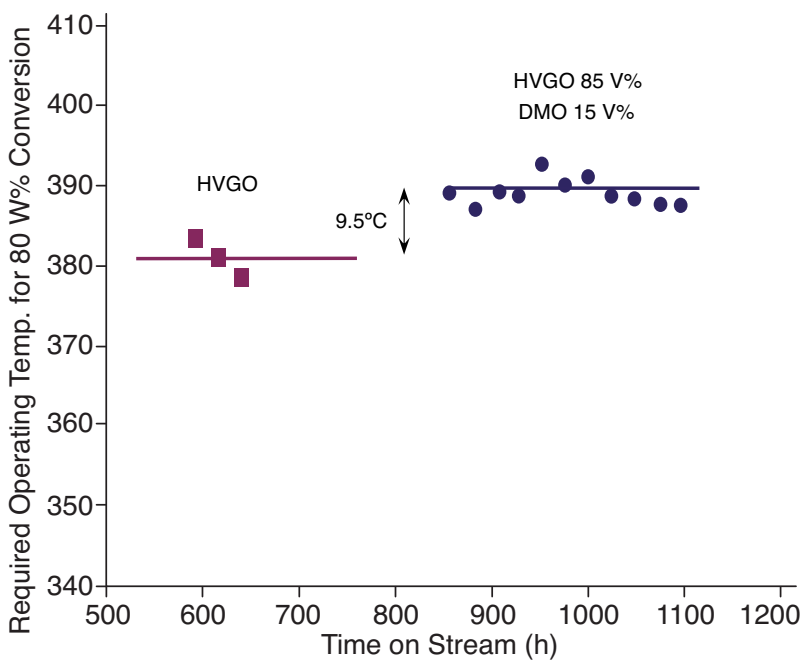

Figure 3

Hydrocracking reactivity of Heavy Vacuum Gas Oil (HVGO) and a mixture $15 \%$ of De-Metallized Oil (DMO) with $85 \%$ HVGO. at the bottom. The commercial hydrocracking unit operating conditions, liquid hourly space velocity (LHSV), hydrogen partial pressure and temperature were applied to achieve the $80 \mathrm{w} \%$ conversion hydrocarbons boiling above $375^{\circ} \mathrm{C}$. The required operating temperature for $\mathrm{HVGO}$ was $381^{\circ} \mathrm{C}$ and increased about $10^{\circ} \mathrm{C}$ higher when the feedstock was blended with $15 \mathrm{~V} \% \mathrm{DMO}$, showing its refractory nature. It is also reported that as the feedstock quality deteriorates, the catalyst stability declines [15]. The rate of catalyst deactivation doubled when the pentane insoluble $\left(\mathrm{C}_{5}\right.$-asphalthenes $)$ of feedstock increased from $0.05 \mathrm{w} \%$ to $2.9 \mathrm{w} \%$.

It is of interest to mention that the bad actors in DMO can be removed and the activity decline can be recovered via a patented method [16].

\section{EXPERIMENTAL}

\subsection{Samples}

The HVGO and DMO were sampled from the vacuum distillation tower and solvent deasphalting unit. The properties of the HVGO and DMO feedstock components are given in Table 1. As can be seen, DMO, which is derived from vacuum residues by solvent de-asphalting, contains high amounts of impurities compared to the vacuum gas oil fractions. The DMO metals content is at acceptable levels that can be handled by utilizing catalyst grading material at the top of the reactor.
TABLE 1

Bulk properties of the hydrocracking feedstocks

\begin{tabular}{l|l|l|l}
\hline Property & Unit & DMO & HVGO \\
\hline Density & $\mathrm{Kg} / \mathrm{Lt}$ & 0.9716 & 0.916 \\
\hline Nitrogen & $\mathrm{ppmw}$ & 1655 & 725 \\
\hline Sulfur & $\mathrm{W} \%$ & 3.17 & 2.19 \\
\hline Hydrogen & $\mathrm{W} \%$ & 11.4 & 12.2 \\
\hline MCR & $\mathrm{W} \%$ & 8.95 & 0.81 \\
\hline C5-Insolubles & $\mathrm{W} \%$ & 0.48 & 0.039 \\
\hline Nickel & $\mathrm{ppmw}$ & 2 & $<1$ \\
\hline Vanadium & $\mathrm{ppmw}$ & 8 & $<1$ \\
\hline
\end{tabular}

\subsection{Mass Spectrometry and lonization Modes}

Crude oils contain heteroatom species (oxygen-, nitrogen-, and sulfur molecules) of different polarities: acidic, basic and neutral molecules. To study these species, an ultrahigh resolution mass spectrometer was utilized with 3 different ionization modes: negative and positive electrospray (ESI+, ESI-) for ionizing acidic and basic species respectively, and atmospheric pressure photo-ionization (APPI) for neutral species [17].

Ultrahigh mass resolution $(R>300000)$ is essential for the correct assignment of elemental compositions $\left(\mathrm{C}_{x} \mathrm{H}_{y} \mathrm{~N}_{z} \mathrm{O}_{v} \mathrm{~S}_{w}\right)$ for complex samples like crude oils. For this study, mass spectra were acquired at the National High Magnetic Field 
Laboratory, Florida State University, Florida, USA, on a custom built FT-ICR mass spectrometer [13] which was equipped with a 9.4 Tesla superconducting magnet [14]. The conditions were reported in the literature $[13,14,18]$. This instrument is capable of resolving signals spaced as closely as $1.1 \mathrm{mDa}\left(\mathrm{SH}_{3}{ }^{13} \mathrm{C}\right.$ vs. $\left.{ }^{12} \mathrm{C}_{4}\right)$ and has been successfully applied for the speciating heteroatom compounds in crude oils [11].

The high resolution mass data is recorded with sufficient precision and mass accuracy to assign an elemental composition to each mass signal in the spectrum. The identified species are then grouped into classes according to the heteroatoms in the elemental composition, e.g., none = pure hydrocarbons, one sulfur (or nitrogen) atom per molecule = monosulfur (or mononitrogen) species, or molecules with one nitrogen and one sulfur atom $=$ sulfur nitrogen species. The elemental compositions were provided from Florida State University as raw data for interpretation.

\subsection{Double Bond Equivalent}

For the following discussion we use the double bond equivalent (DBE) as a convenient measure for the aromatic characteristics of a molecule [19]. The DBE is defined as the number of hydrogen atoms lacking from an elemental composition in comparison to the corresponding saturated molecule with otherwise identical number of carbon and heteroatoms. Every double bond or ring in a molecule reduces the number of hydrogen atoms by two. For example, hexane has a DBE of zero as it is fully saturated and contains no ring. Cyclohexane contains one ring and hence features a DBE of one. Benzene features one ring and three double bonds and hence has a DBE value of four. The obtained mass spectrometric data are plotted as DBE vs. carbon numbers for all species of each heteroatom class and for pure hydrocarbon species. The size of each dot in these diagrams reflects the underlying mass spectral signals relative intensity. The mass spectrometric intensities can not be compared between different species and ionization modes due to largely differing response factors.

\section{RESULTS AND DISCUSSION}

\subsection{Sulfur Species}

The modified van Krevelen diagrams [20] in Figure 4 below present the data obtained for all sulfur species in the HVGO (on the left) and DMO (on the right). All identified sulfur species are included in the map, rendering it easy to distinguish species with one (mono), two (di), or three (tri) sulfur atoms per molecule. The plots show the ratio of carbon to hydrogen atoms as an indicator for the aromaticity of each individual elemental composition versus the ratio of sulfur atoms to carbon atoms in each identified elemental composition. In addition to plotting thousands of molecules in one graph, these plots allow for convenient comparisons between samples.

The modified van Krevelen plot of the HVGO (Fig. 4) shows the highest abundance for monosulfur species, which
HVGO-APPI-S1-S3

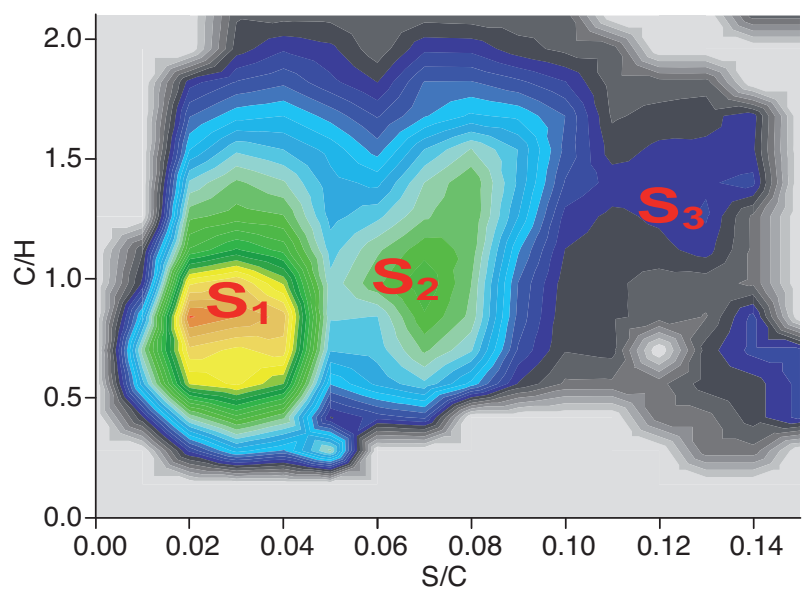

DMO-APPI-S1-S3

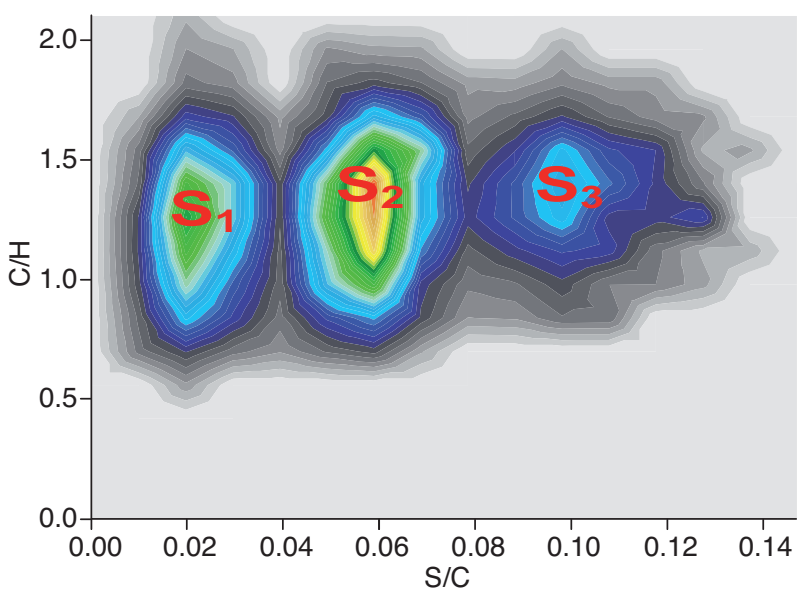

Figure 4

Modified van-Krevelen plot showing the sulfur species found in the HVGO (left) and DMO (right). The axes of the plot are the C/H ratio, representing an increasing aromaticity of the depicted species the higher they appear in the graph, versus the sulfur over carbon atoms ratio per molecule. 
are also the most abundant sulfur species found in the crude oil from which HVGO originated [19]. A significant amount of disulfur species and some trisulfur species have been identified as well.

Mono-, di-, and trisulfur species were also identified in DMO with disulfur species being the more abundant (Fig. 4). Trisulfur species are also relatively more enriched in the DMO. This distribution of sulfur species in the DMO differs from what has been detected in the original feedstock, Arabian Light crude oil, or the HVGO fraction, where monosulfur species are the dominant sulfur species. The aromaticity and number of sulfur atoms per molecule apparently increase with increasing boiling point of the analyzed stream. Significant amounts of di- and trisulfur species may explain the higher total sulfur content observed in the DMO. Whether the sulfur atoms are present in two or three isolated aromatic rings or as part of one larger condensed aromatic system have yet to be investigated for Arabian oils [21]. This may explain the observed difficulties in the hydrocracking of the DMO.

\subsection{Monosulfur Species}

There are 778 individual monosulfur species identified in the HVGO. Their combined intensities account for $23.8 \%$ of all measured signals. The number of carbon atoms ranges from 17 (e.g., $\mathrm{C}_{17} \mathrm{H}_{19} \mathrm{~S}_{1}$, with a measured mass of $255.12041 \mathrm{Da}$ ) to 48 (e.g., $\mathrm{C}_{48} \mathrm{H}_{74} \mathrm{~S}_{1}$, with a measured mass of 682.55074 Da) and their DBE extends from 2 to 24 , corresponding to a thiophene with up to seven aromatic rings per molecule with the remaining carbon atoms as alkyl substituents on the ring (Table 2).

TABLE 2

Data summary of all identified sulfur species in HVGO and DMO

\begin{tabular}{l|c|c}
\hline Sulfur Types & HVGO & DMO \\
\hline Mono & 778 species & 764 species \\
\hline Carbon Atoms & $17-48$ & $22-50$ \\
\hline DBE & $2-24$ & $7-32$ \\
\hline aromatic rings & 1 to 7 & Up to 11 \\
\hline Di & 494 species & 606 species \\
\hline Carbon Atoms & $14-43$ & $21-48$ \\
\hline DBE & $7-24$ & $10-31$ \\
\hline Aromatic rings & Up to 8 & Up to 10 \\
\hline Tri & 59 species & 315 species \\
\hline Carbon Atoms & $20-41$ & $22-42$ \\
\hline DBE & $10.5-21$ & $14-29$ \\
\hline Thiophene aromatics & $3-7$ & $5-10$ \\
\hline
\end{tabular}

In the mass spectrum of the DMO, 764 individual monosulfur species were identified as shown in Figure 5. All identified sulfur species are summarized in Table 2. The combined intensities of all disulfur species account for $25.5 \%$ of
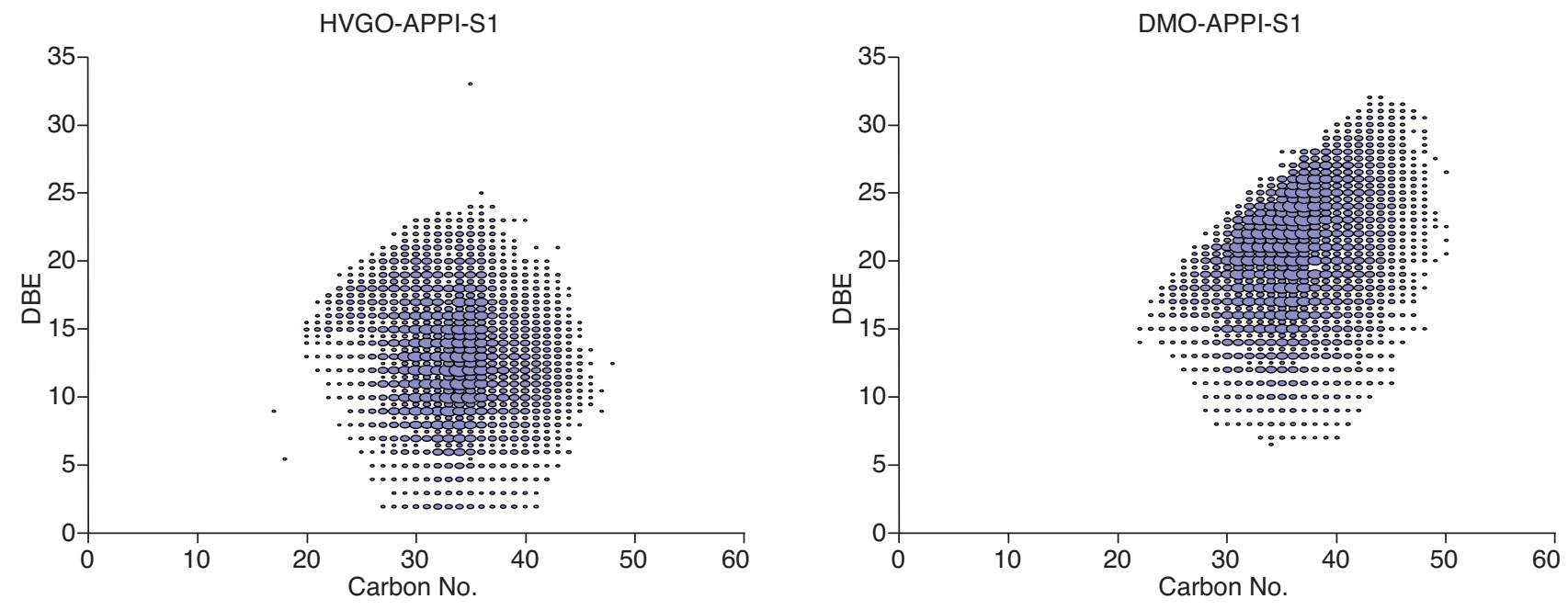

Figure 5

Carbon number versus DBE values for the signals identified as monosulfur compounds. Data is shown for the HVGO (left) and DMO (right). 

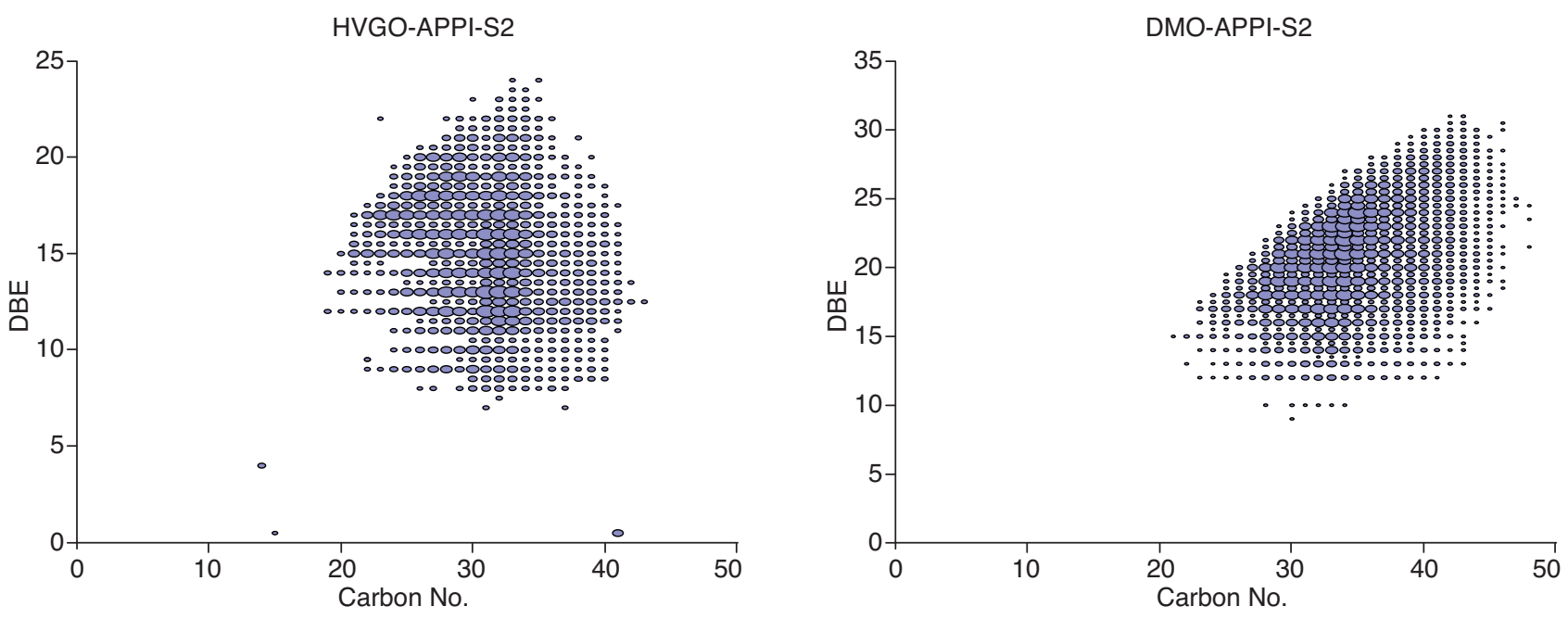

Figure 6

Carbon number versus DBE values for the species identified as disulfur compounds. Data is shown for the HVGO (left) and DMO (right).

all measured signals in the mass spectrum. The number of carbon atoms per molecule ranges from 22 to 50 and DBE values extend from 7 to 32 , corresponding to molecules with up to 11 aromatic rings (benzonapthothiophenes) with large alky substituents that account for the remaining carbon atoms.

Generally, it can be concluded that the sulfur species in the DMO feature an overall slightly higher carbon number and are more aromatic in terms of DBE than those in the HVGO.

It should be noted that the linear slanted edge observed in the upper left side of the DBE $v s$. carbon number graph of the DMO (Fig. 5) can be explained by the limit of the theoretical maximum number of aromatic rings for a given number of carbon and hydrogen atoms. The species at this $\mathrm{C} / \mathrm{H}$-limit have no alkyl carbon atoms; all carbon atoms are embedded in the aromatic system.

\subsection{Disulfur Species}

There are 494 individual disulfur species identified in the HVGO. The corresponding carbon number $v s$. DBE plot is shown in Figure 6. The combined intensity of all S2 species accounts for $9.2 \%$ of all measured signals. The carbon numbers of the identified species ranges from 14 (e.g., $\mathrm{C}_{14} \mathrm{H}_{23} \mathrm{~S}_{2}$, with a measured mass of $255.12396 \mathrm{Da}$ ) to 43 (e.g., $\mathrm{C}_{43} \mathrm{H}_{64} \mathrm{~S}_{2}$, with a measured mass of 644.4443 Da) with DBE values extending from 7 to 24 . The DBE value of eight is consistent with structures containing two thiophene rings and one benzene ring, e.g., thiophenobenzothiophene. Whether these two thiophene rings are adjacent or separated by the benzene ring cannot be concluded from the data.

The mass spectrum of the DMO contains 606 disulfur species with carbon numbers ranging from 21 to 48 carbon atoms and DBE values from 10 to 31 (Fig. 6), consistent with 4 to 11 aromatic rings per molecule. The combined intensity of all S2 species accounts for $16 \%$ of all measured signals.

Again, the theoretical maximum number limit of carbon atoms to makeup the aromatic ring system is visible from the slant shaped edge in the upper left side of the DBE vs. carbon number plot (Fig. 6). The structures of the $\mathrm{S} 2$ species are closer to the maximum limit of aromaticity than the structures observed for the monosulfur species. This implies that disulfur species are more aromatic in terms of DBE values than the monosulfur species.

\subsection{Trisulfur Species}

Only 59 trisulfur species with a combined relative abundance of $0.5 \%$ were identified in the mass spectrum of the HVGO (Fig. 7). Carbon numbers extend from 20 (e.g., $\mathrm{C}_{20} \mathrm{H}_{19} \mathrm{~S}_{3}$, with a measured mass of $344.98595 \mathrm{Da}$ ) to 41 (e.g., $\mathrm{C}_{41} \mathrm{H}_{61} \mathrm{~S}_{3}$, with a measured mass of $649.3926 \mathrm{Da}$ ), but the data on trisulfur species is too sparse to draw further conclusions for the HVGO. On the contrary, the DMO features a significant number of trisulfur species (315), accounting for $4.5 \%$ of all the measured signals. Their carbon numbers extend from 22 to 42 carbon atoms and DBE values from 14 to 29 , corresponding to 5 (e.g., dithiophenodibenzothiophene) to 10 aromatic rings per molecule. 

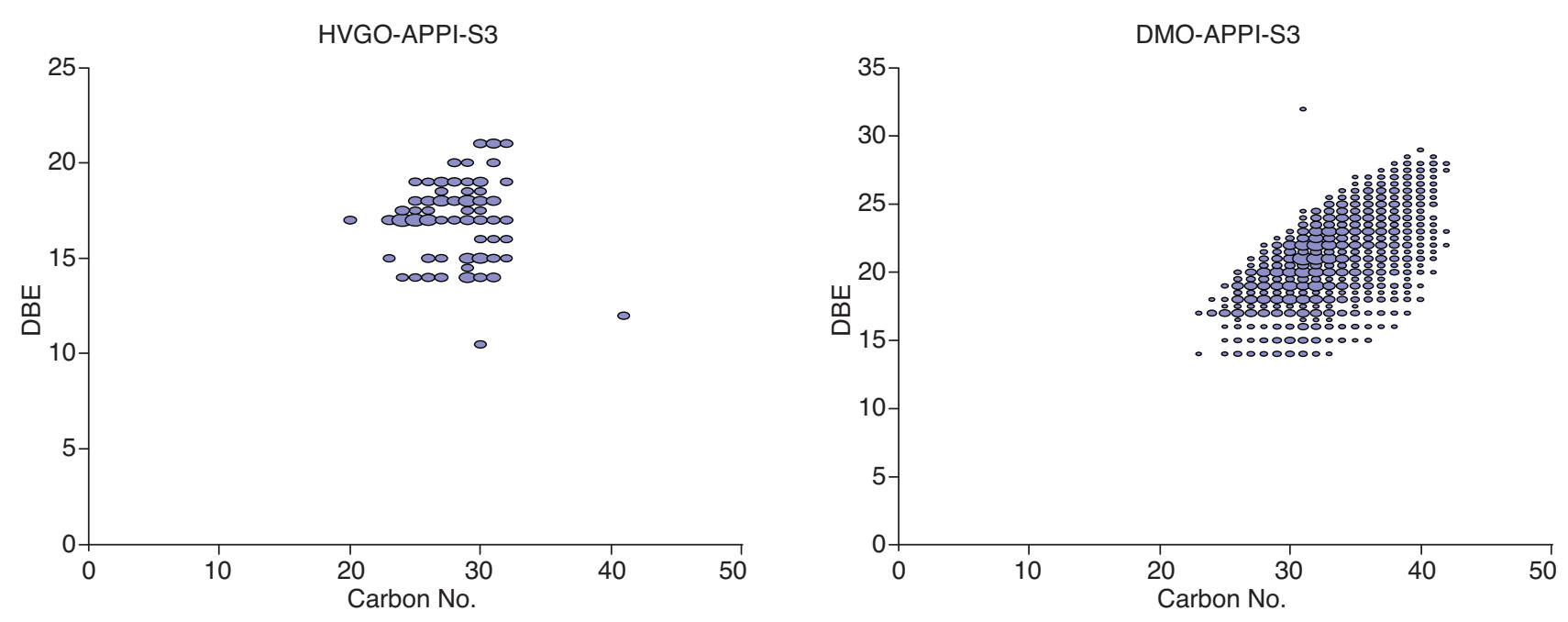

Figure 7

Carbon number versus DBE values for the trisulfur compounds. Data is shown for the HVGO (left) and DMO (right).

Table 2 summarizes the number of species per group, the mass and carbon ranges as well as the DBE values and the expected number of rings in all S1, S2 and S3 species in the HVGO and DMO.

\subsection{Aromatic Hydrocarbons}

HVGO and DMO contain $0.81 \mathrm{w} \%$ and $8.95 \mathrm{w} \%$ of Micro Carbon Residue (MCR), respectively. This is reflected in the overall characteristics of the individual hydrocarbon molecular species in both fractions as shown in Figure 8.

Hydrocarbon molecules with carbon numbers ranging from $20\left(\right.$ e.g., $\mathrm{C}_{20} \mathrm{H}_{15}$, with a measured mass of $\left.255.11654 \mathrm{Da}\right)$ to 46 (e.g., $\mathrm{C}_{46} \mathrm{H}_{69}$, with a measured mass of $621.53938 \mathrm{Da}$ ) and from 23 to 49 and accounting for about $6.0 \%$ each of all measured signals were identified in $\mathrm{HGVO}$ and DMO, confirming that DMO is slightly heavier than HVGO as expected. DBE values in the HVGO range from 5 to 24 , corresponding to 1 to 7 aromatic rings, whereas DBE values for the DMO range from 7 to 32 , consistent with 2 to 10 aromatic rings. These findings confirm that the overall aromaticity of the two fractions differs significantly from one another with the DMO being the heavier. Therefore, it is expected that the DMO, that contains more aromatic species, demands more severe hydrocracking conditions.

\subsection{Nitrogen Species}

Nitrogen species of significantly varying polarities have been described in petroleum samples [21]. Three different mass spectrometric ionization techniques have been proven powerful for ionizing these different types of nitrogen molecules according to their polarities [22]. Negative electrospray ionization (ESI negative) is selective for molecules susceptible to deprotonation, e.g., acids and pyrroles. ESI in positive mode has been used for enhanced ionization of basic molecules through protonation. Atmospheric pressure photoionization (APPI) in positive mode produces radical molecular ions as well as protonated ions, e.g., neutral hydrocarbons, thiophenic sulfur compounds and pyrrolic or pyridinic nitrogen compounds, respectively.

\subsection{Nitrogen Compounds Detected by APPI}

A large number of nitrogen containing species were found in the HVGO and DMO. Figure 9 shows a modified vanKrevelen contour plot of the ratio of carbon atoms over hydrogen atoms $(\mathrm{C} / \mathrm{H})$ versus the ratio of nitrogen atoms over carbon atoms $(\mathrm{N} / \mathrm{C})$ for the nitrogen species identified in the HVGO on the left and for the DMO on the right. A higher $\mathrm{C} / \mathrm{H}$ ratio indicates an overall higher aromaticity per molecule. The distribution of N1 and N2 compounds in both feedstock streams can be readily identified as seen in Figure 9. The modified van-Krevelen map of nitrogen compounds in the DMO shows species with an overall higher carbon to hydrogen ratio, for both mono and dinitrogen compounds, than in the HVGO. Additionally, dinitrogen species seem to be more concentrated in $\mathrm{DMO}$, where a larger number of signals with a slightly higher abundance could be identified. Data for all nitrogen species detected using APPI mode are 

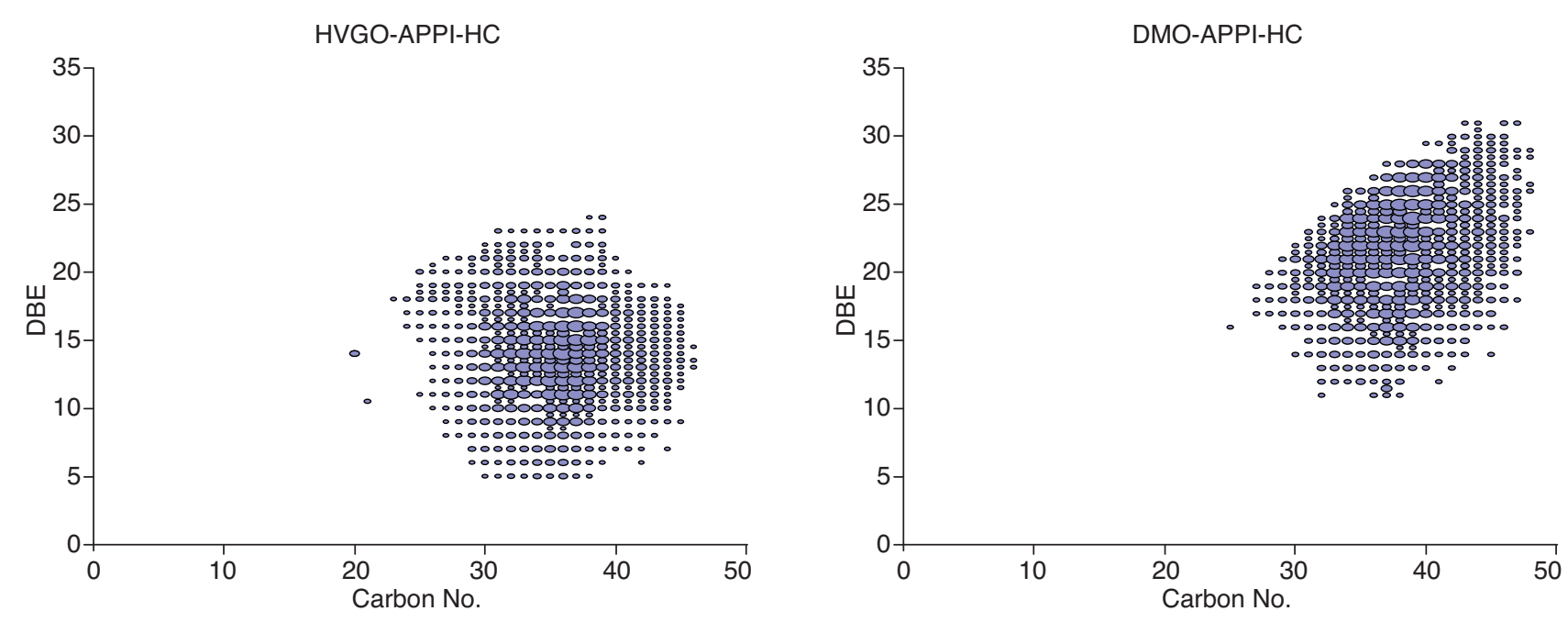

Figure 8

Carbon number versus DBE values for the identified aromatic hydrocarbon species. Data is shown for the HVGO (left) and DMO (right).
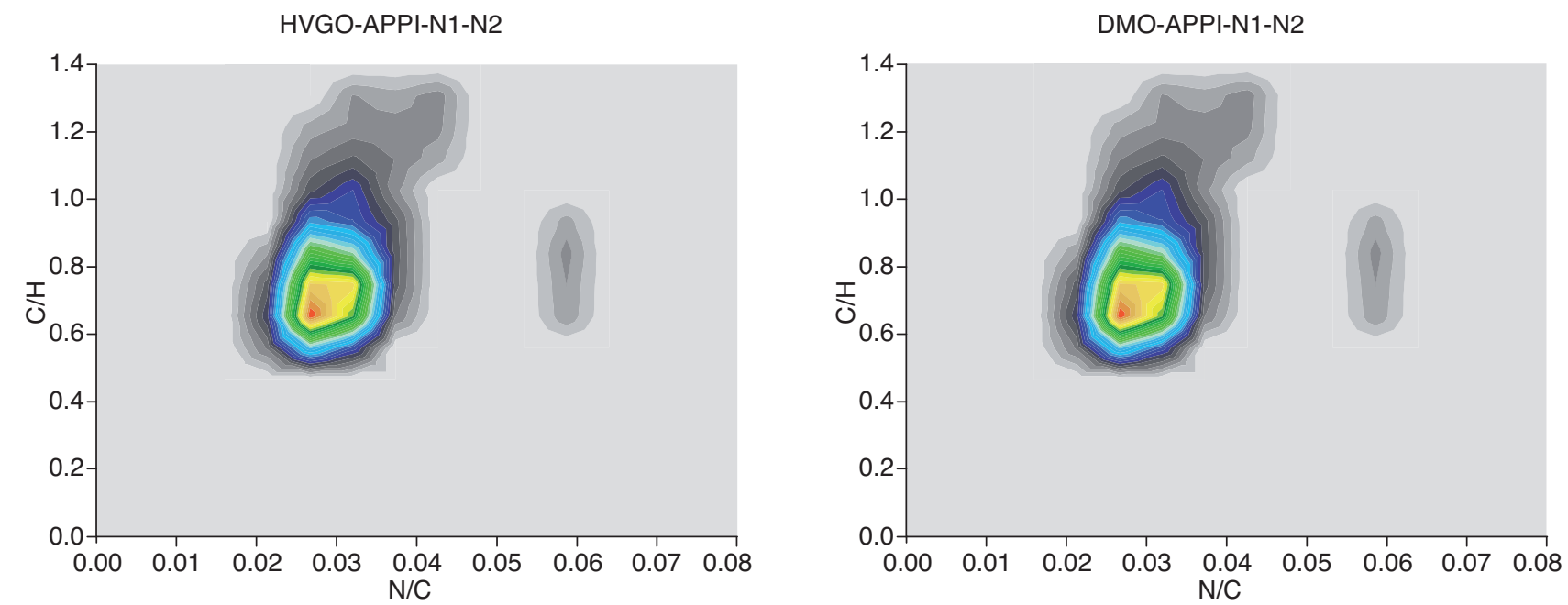

Figure 9

Modified van-Krevelen graph showing the nitrogen species found in the HVGO and DMO. The axes of the plot are the $\mathrm{C} / \mathrm{H}$ ratio, representing the aromaticity of the depicted species versus N/C ratio.

summarized in Table 3. The overall molecular mass range of mononitrogen species is slightly higher for the elemental compositions identified in the DMO. The mass spectral data are in agreement with the bulk analytical data that DMO has higher aromaticity as reflected by its higher DBE values than can be found in the HVGO.

The total relative abundance of the N1 compounds accounts for $14 \%$ of all species identified using APPI. The measured molecular masses of the mononitrogen species (N1) extend from 308 to $684 \mathrm{Da}$ in the HVGO. There are 476 mononitrogen species detected in $\mathrm{HVGO}$ with a carbon number extending from 23 (e.g., $\mathrm{C}_{23} \mathrm{H}_{18} \mathrm{~N}_{1}$, with a measured mass of $308.14326 \mathrm{Da})$ to $49\left(\right.$ e.g., $\mathrm{C}_{49} \mathrm{H}_{82} \mathrm{~N}_{1}$, with a measured mass of 684.64440 Da). DBE values range from 4 to 23 which corresponds to nitrogen species with one aromatic ring (pyridine) to six aromatic rings (e.g. benzonaphthoacridine) 
with a large number of carbon atoms in the form of alkyl substituents on the aromatic ring system. There are 597 mono $\mathrm{N} 1$ species found in the DMO with a total relative abundance of $11.5 \%$ and a molecular weight ranging from $345 \mathrm{Da}$ to $778 \mathrm{Da}$ with 26 to 56 carbon atoms per molecule. DBE values for all species in the DMO range from 7 to 31.5 , corresponding to 2 to 10 aromatic rings per molecule, e.g., dibenzoacridine with large alkyl substituents on the aromatic ring system.

TABLE 3

Summary of all nitrogen species in HVGO and DMO identified using APPI

\begin{tabular}{l|c|c}
\hline Nitrogen Types & HVGO & DMO \\
\hline Mono & 476 species & 597 species \\
\hline Carbon Atoms & $23-49$ & $26-56$ \\
\hline DBE & $4-23$ & $7-31$ \\
\hline aromatic rings & $1-7$ & $2-10$ \\
\hline Di & 19 species & 59 species \\
\hline Carbon Atoms & $33-36$ & $34-44$ \\
\hline DBE & $12-19$ & $16-25$ \\
\hline Aromatic rings & $4-6$ & $5-8$ \\
\hline
\end{tabular}

Both HVGO and DMO contain a significant number of aromatic species with two nitrogen atoms per molecule referred to as dinitrogen species (N2). The abundance of the $\mathrm{N} 2$ species in the HVGO is relatively lower than those in the DMO (0.11\% versus $0.37 \%)$ and includes mostly pyridinetype species. DBE values for dinitrogen species in the HVGO range from 12 to 19 , corresponding to 4 (e.g., benzocarbazole) to 7 aromatic rings with alkyl carbon numbers ranging from 33 (e.g., $\mathrm{C}_{33} \mathrm{H}_{46} \mathrm{~N}_{2}$, with a measured mass of $470.36538 \mathrm{Da}$ ) to $36\left(\right.$ e.g., $\mathrm{C}_{36} \mathrm{H}_{53} \mathrm{~N}_{2}$, with a measured mass of 513.42040 $\mathrm{Da})$. The DMO has a wider molecular weight distribution with carbon numbers ranging from 34 up to 44 and overall higher aromatic characteristics. DBE values range from 16 to 25 , corresponding to 7 to 10 aromatic rings per molecule.

\subsection{Basic and Nonbasic Nitrogen Species}

The mononitrogen compounds in both HVGO and DMO can be grouped into two main categories of different polarity: pyridine and pyrrole type nitrogen species [23]. The first type is basic in nature and is a known poison to hydrotreating/hydrocracking catalysts, while the latter is neutral, less reactive and hard to remove by hydrotreating [24].

The difference in polarities of these two nitrogen types allows us to distinguish between them in the APPI mass spectra. Pyridine type nitrogen heterocycles are susceptible to protonation during the ionization process and form proto- nated ions. Therefore, pyridine type nitrogen species feature integer DBE values, while pyrroles are not protonated but rather form radical cations. Therefore, pyrrole type species feature decimal DBE values in APPI mass spectra. Both HVGO and DMO are found to be dominated by pyridinebased aromatic species (Fig. 10). The abundance of the pyridinic species accounts for $13.2 \%$ and $10.0 \%$, while that of the pyrrolic species accounts for $1.2 \%$ and $1.5 \%$ off all measured signals in HVGO and DMO respectively.

The pyrrole-based species in the HVGO start with DBE values of 9.5 to 20.5, corresponding to 3 (benzocarbazole) to 7 aromatic rings (pyrroles to carbazoles with further aromatic rings in the molecule) with a total number of 28 (e.g., $\mathrm{C}_{28} \mathrm{H}_{31} \mathrm{~N}_{1}$, with a measured mass of $344.98595 \mathrm{Da}$ ) to 44 carbon atoms as core and alkyl substituents. The pyrrole-based species in the DMO are relatively more abundant than in the HVGO, with DBE values extending from 14.5 to 31.5, corresponding to 5 (e.g., dibenzocarbazole) to 11 aromatic rings (carbazole benzologues) with a total number of 29 to 45 carbon atoms as core and alky substituents. Generally, it can be concluded that the DMO contains larger pyrrole-type nitrogen structures with higher aromatic characteristics as indicated by their DBE values than the HVGO.

\subsection{Nitrogen Compounds Identified by ESI Positive Mass Spectral Mode}

Pyridine is a common basic substructure in nitrogen containing aromatic molecules in petroleum samples. Molecules that contain a pyridine ring are selectively detected by ESI positive mode due to their high polarity; explaining the large number of pyridinic nitrogen species observed in this ionization mode.

The modified van-Krevelen plots (Fig. 11) of the identified nitrogen species in HVGO (left) and DMO (right) show contour maps of the nitrogen species in the samples. The N2 species are relatively more concentrated in the DMO, but N1 and N2 species have a similar aromaticity. The positive ESI data of all identified nitrogen species are summarized in Table 4.

The total relative abundance of the $\mathrm{N} 1$ compounds observed using ESI in positive mode in the HVGO accounts for $43.3 \%$ of all observed species (Fig. 12). The measured molecular masses extend from $334 \mathrm{Da}$ to $742 \mathrm{Da}$ in the HVGO mass spectrum with 404 individual mononitrogen containing species detected (likely acridines). Carbon numbers extend from 24 to 53 carbon atoms per molecule and DBE values range from 5 to 22 . These DBE values correspond to 3 (acridine) to 7 aromatic rings per molecule (dinaphthoacridine) with additional carbon atoms in the form of alkyl substituents on the aromatic systems.

The data reveals higher carbon numbers and DBE values for the N1 species in the DMO than in the HVGO as depicted 

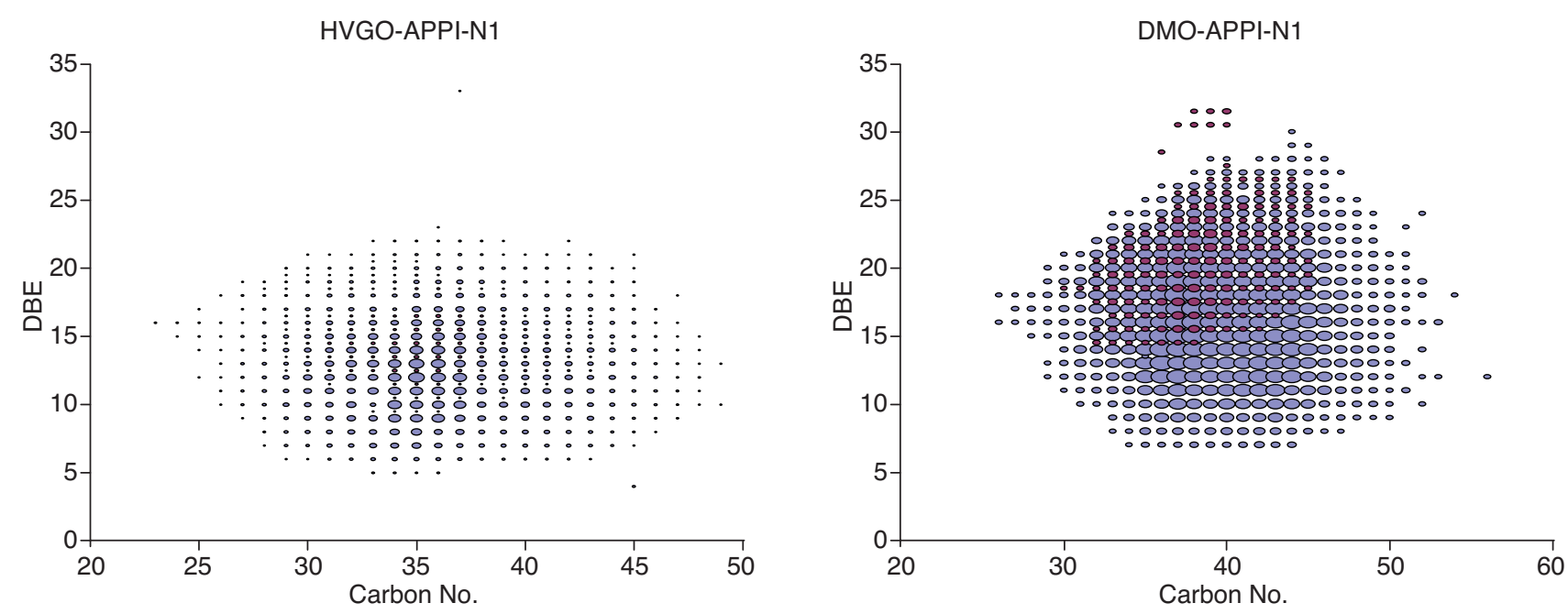

Figure 10

DBE versus carbon numbers for mononitrogen species in the HVGO and DMO as determined by APPI. The size of the dots represents the relative intensity of the underlying mass signal. The blue dots denote molecules that contain a nitrogen atom in an assumed pyridine substructure and red dots denote nitrogen compounds with a pyrrole substructure.
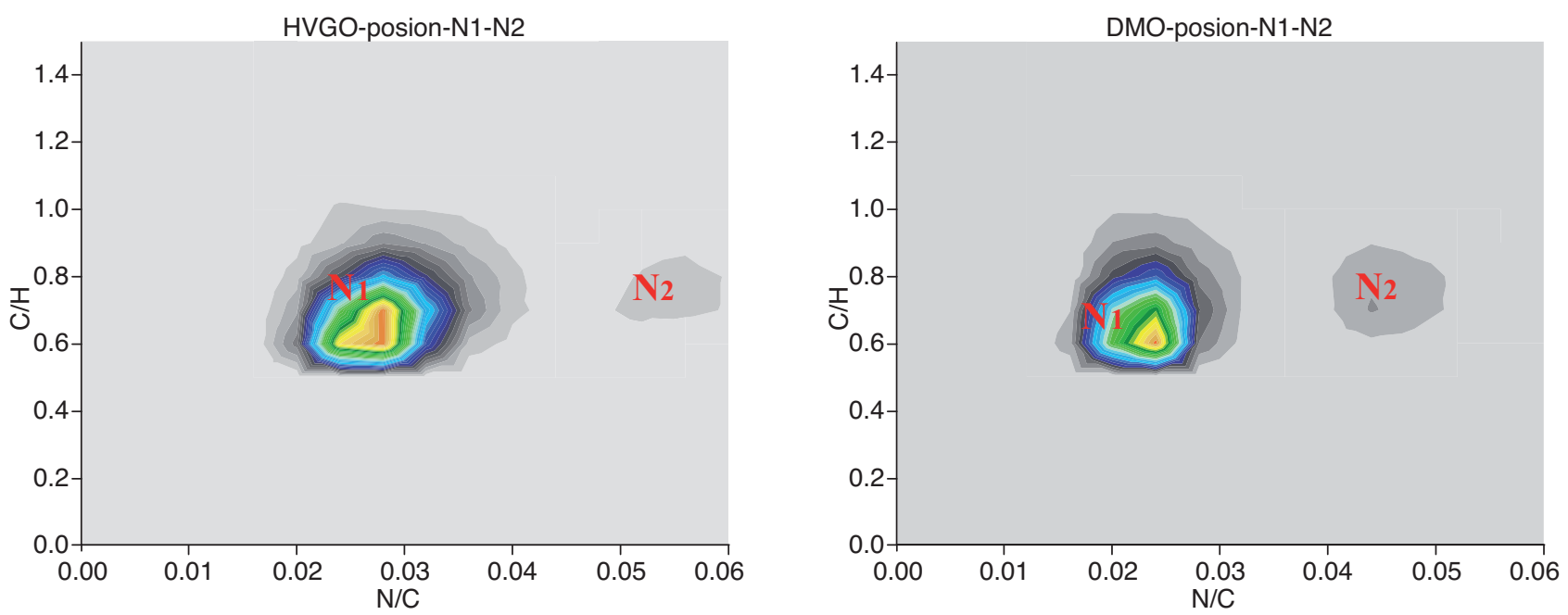

Figure 11

Modified van-Krevelen graph showing all nitrogen species found by ESI in the positive mode in the HVGO (left) and DMO (right). The axis of the plot denotes the $\mathrm{C} / \mathrm{H}$ ratio which represents the aromaticity of the identified species versus the N/C ratio.

in Figure 12. There have been 490 mononitrogen species identified in the DMO, with a combined relative abundance of $37.5 \%$ of all identified mass signals. The molecular masses extend from $400 \mathrm{Da}$ to $836 \mathrm{Da}$ with 29 to as many as 60 carbon atoms per molecule. DBE values range from 5 to 25 , corresponding to acridines with up to six benzyl rings in the same molecule (e.g., dinaphthoacridine) with the remain- ing carbon atoms as alkyl substituents. It has to be noted that all the detected N1 compounds in both HVGO and DMO are found as protonated ions and it can be, therefore, concluded that the nitrogen atom is located in pyridinic substructures.

There are 103 different dinitrogen compounds identified in the HVGO by positive ESI mode (Fig. 13). The total relative abundance of mass signals that have been identified as 
TABLE 4

Summary of all nitrogen species in HVGO and DMO identified using ESI in the positive mode

\begin{tabular}{l|c|c}
\hline Nitrogen Types & HVGO & DMO \\
\hline Mono & 404 species & 490 species \\
\hline Carbon Atoms & $24-53$ & $29-60$ \\
\hline DBE & $5-22$ & $5-25$ \\
\hline aromatic rings & $2-7$ & $2-8$ \\
\hline$D i$ & 103 species & 168 species \\
\hline Carbon Atoms & $30-44$ & $37-52$ \\
\hline DBE & $9-19$ & $10-24$ \\
\hline Aromatic rings & $3-6$ & $3-8$ \\
\hline
\end{tabular}

N2 species accounts for $1 \%$ of all signals. The observed molecular masses range from $429 \mathrm{Da}$ to $621 \mathrm{Da}$ with carbon numbers ranging from 30 to 44 carbon atoms. DBE values of the molecules range from 9 to 19 , corresponding to 3 to 6 aromatic rings per molecule.

There have been 168 different N2 species identified in the DMO, adding up to a total relative abundance of $2 \%$ of all identified signals. Molecular masses extend from 515 to 723 and carbon numbers range from 30 to 52 . DBE values range from 9 to 25 , corresponding to 3 to 8 aromatic rings per molecule. From the data it is apparent that the heavier DMO contains more $\mathrm{N} 2$ species with higher aromatic characteristics than the HVGO.

\subsection{Nitrogen Compounds Identified by ESI Negative Mass Spectral Mode}

ESI in the negative mode detects largely ions formed by deprotonation. The negative mode, therefore, selectively detects neutral pyrrole type nitrogen species over basic pyridine type species, which are much less susceptible to deprotonation. An aromaticity map of the neutral nitrogen components in HVGO and DMO is displayed in the modified van-Krevelen plots in Figure 14. The data of all the nitrogen compounds obtained using negative ESI mode is listed in Table 5.

TABLE 5

Summary of the nitrogen species in HVGO and DMO identified using ESI in the negative mode

\begin{tabular}{l|c|c}
\hline Nitrogen Types & HVGO & DMO \\
\hline Mono & 292 species & 335 species \\
\hline Carbon Atoms & $19-48$ & $31-64$ \\
\hline DBE & $9-21$ & $9-25$ \\
\hline aromatic rings & $3-7$ & $3-8$ \\
\hline
\end{tabular}

There were 292 individual N1 species identified in the mass spectra of the HVGO as shown in Figure 15. The total relative abundance for all mass signals is $41 \%$ and the molecular weight ranges from $258 \mathrm{Da}$ to $670 \mathrm{Da}$ with 19 to 48 carbon atoms per molecule. DBE values range from 9 to
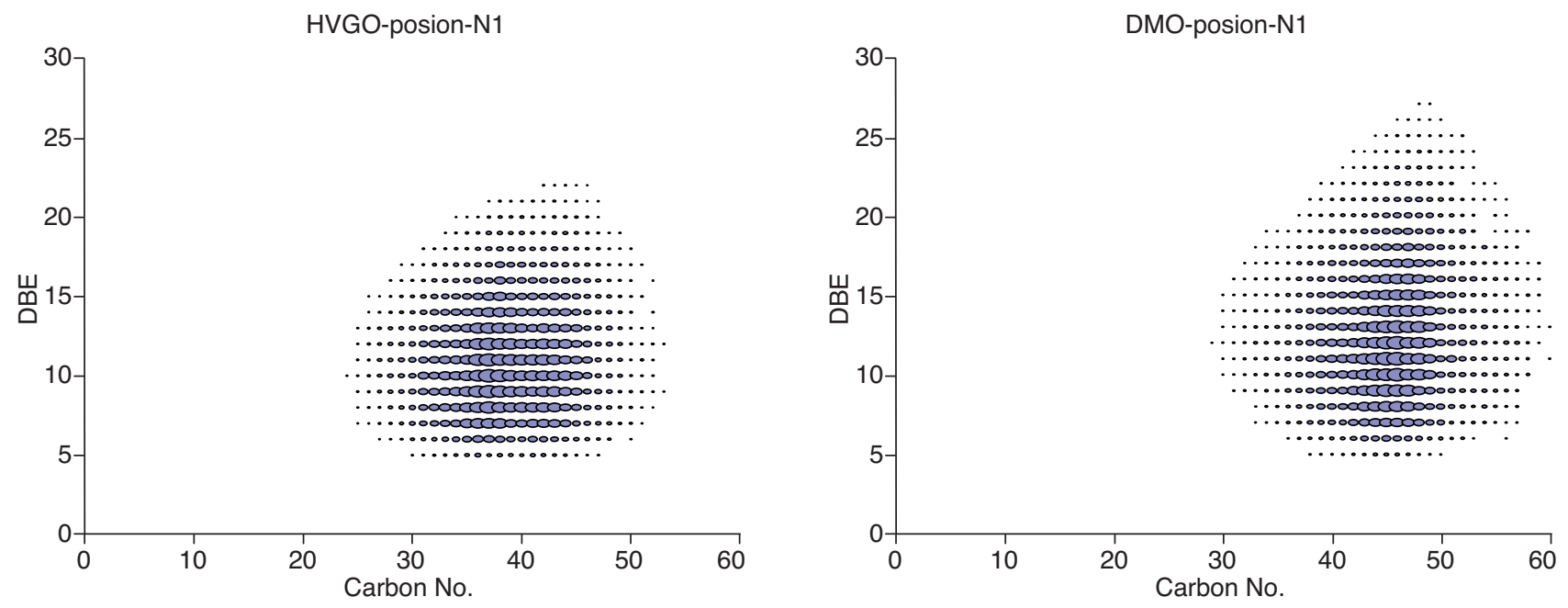

Figure 12

DBE versus carbon numbers for mononitrogen species in the HVGO and DMO detected by ESI in the positive mode. The size of the dots represents the relative intensity of the underlying mass signal. 

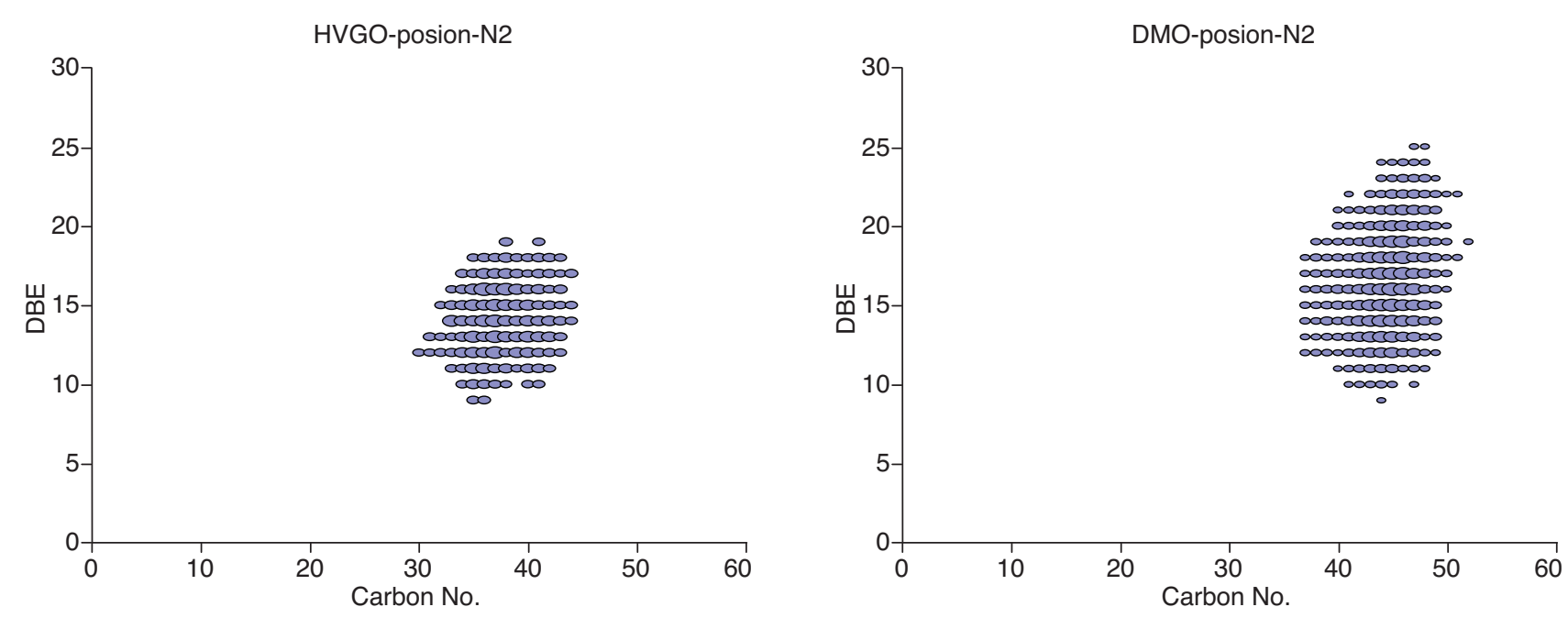

Figure 13

DBE versus carbon numbers for dinitrogen species in the HVGO and DMO detected by ESI in the positive mode. The size of the dots represents the relative intensity of the corresponding mass signals.
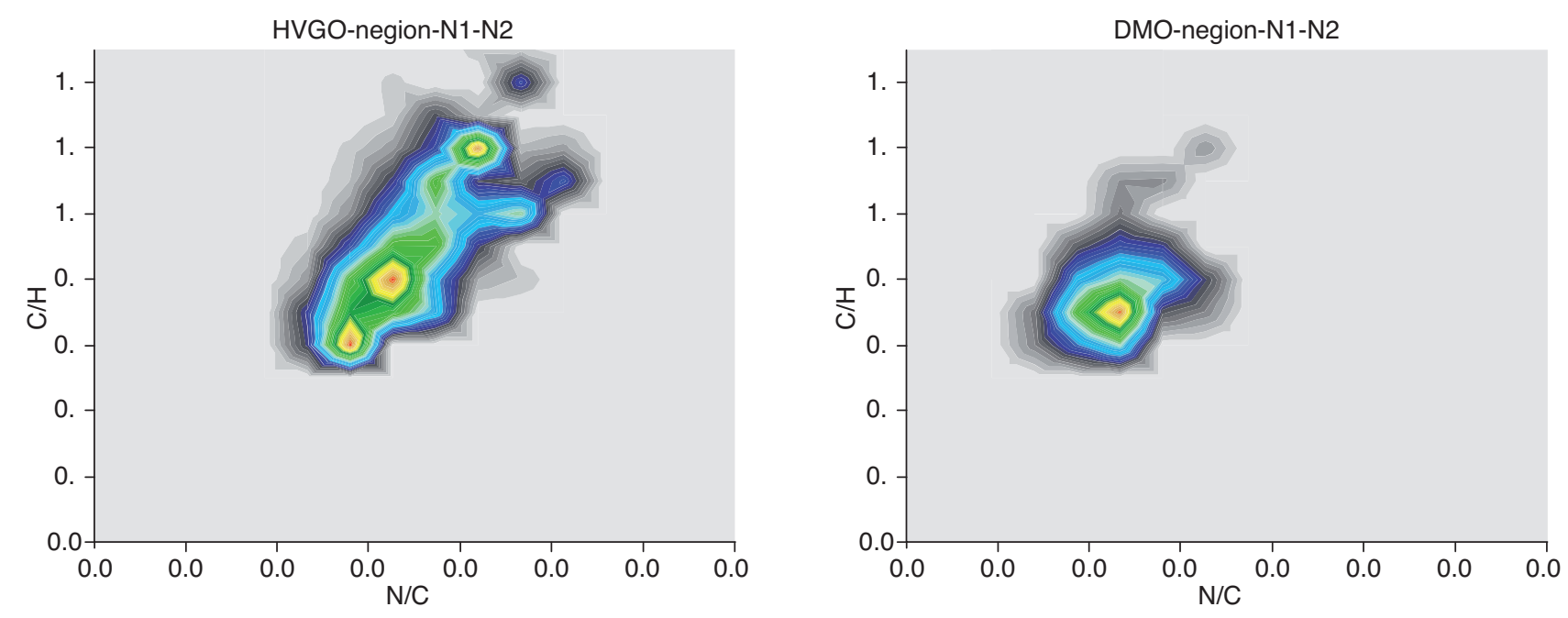

Figure 14

Modified van-Krevelen plot showing the nitrogen species found in the HVGO (left) and DMO (right) by positive mode electrospray ionization. The axes of the plot are the $\mathrm{C} / \mathrm{H}$ ratio, representing an increasing aromaticity of the depicted species the higher they appear in the graph, versus the nitrogen over carbon atoms per molecule ratio.

21 , corresponding to 3 (carbazole) to 7 aromatic rings, including a pyrrole substructure in each molecule (e.g., dinaphthocarbazole).

The mass spectrum of the DMO contains 335 different N1 species with molecular masses ranging from 410 Da to 978 $\mathrm{Da}$, corresponding to 31 to 64 carbon atoms per molecule.
The total relative abundance for all mass signals is $9 \%$. DBE values extend from 9 to 25 , corresponding to carbazoles with up to eight aromatic rings per molecule. These larger aromatic systems in the DMO in comparison to that in the HVGO are in agreement with the higher micro carbon residue (MCR) value (Table 1). 

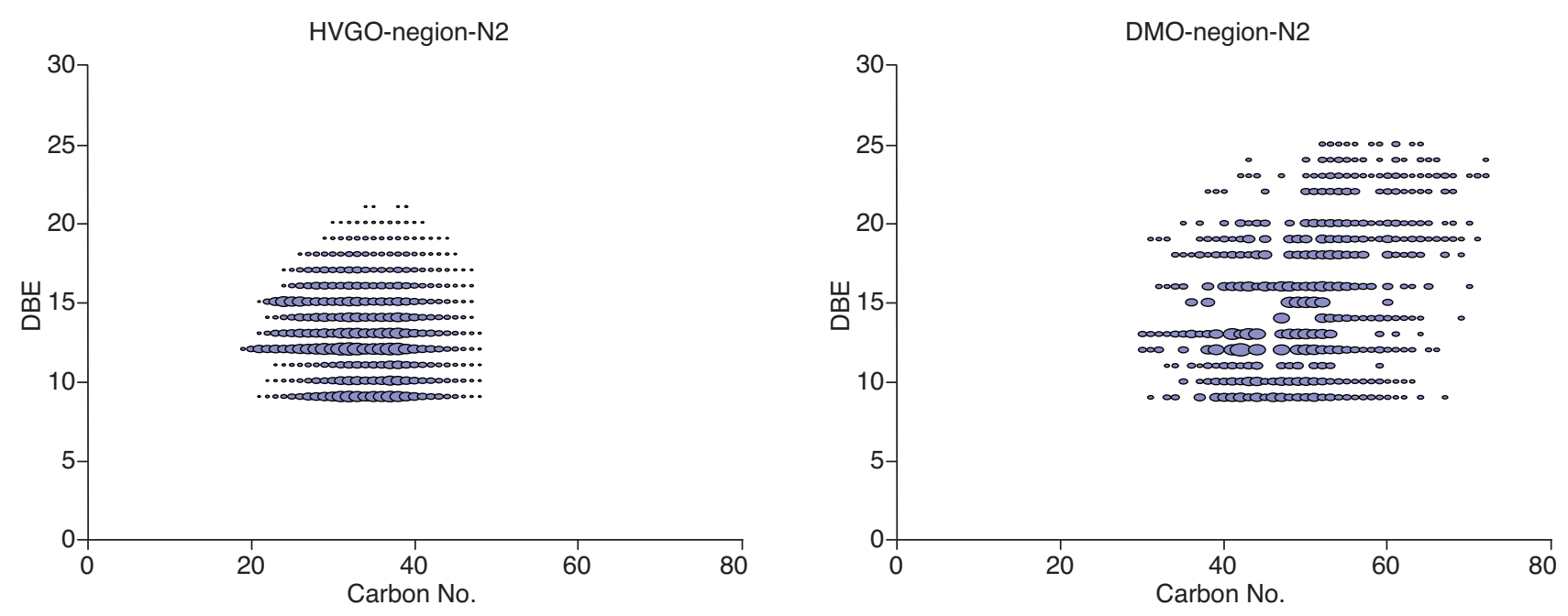

Figure 15

DBE versus carbon numbers for mononitrogen species in the HVGO and DMO detected by ESI in the negative mode. The size of the dots represents the relative intensity of the corresponding mass signals. The apparent gaps in the DMO data are due to measuring artifacts.

\section{CONCLUSION}

Hydrocracking feedstock Heavy Vacuum Gas Oil (HVGO) and De-Metallized Oil (DMO) were characterized on the molecular level to understand their nature and behavior for processing purposes. Detailed information on the hetero atom species in terms of class and type, namely present hetero atoms, carbon numbers, and extent of aromaticity (DBE) has been discussed.

Sulfur species. Mono-, di-, and trisulfur species were identified in both, HVGO and DMO, with disulfur species being the most abundant sulfur class in the DMO. This is a remarkable finding because Arabian Light crude oil from which DMO has originated contains a significantly higher ratio of monosulfur compounds compared to disulfur compounds, indicating that disulfur compounds have been concentrated in the DMO. The aromaticity as measured by DBE of the sulfur species correlates roughly linearly to the number of sulfur atoms per molecule: monosulfur species are less aromatic than disulfur species, which again have a lower aromaticity than trisulfur species. The trisulfur species are overall close to the maximum aromaticity limit of the molecules, with a high portion of the carbon atoms used up in the aromatic rings and only a smaller number of carbon atoms remaining as alkyl substituents.

Nitrogen species. A large number of mono- and dinitrogen species have been found in both feedstocks. The gained knowledge of their elemental composition allows drawing conclusions on the chemical structures, which is important as the reactivity of aromatic nitrogen compounds decreases with increasing molecular weight [25]. Moreover, various ionization modes were exploited to enhance the detection of nitrogen compounds of different polarities. Two main types of nitrogen species have been identified in both HVGO and DMO: basic pyridines and neutral pyrroles. Differentiation between basic pyridine type species and neutral, pyrrole type nitrogen species helps understanding the impact of a feedstock on the hydrocracking process performance. The pyridine type structures are a known poison to hydrotreating/hydrocracking catalysts, while the pyrrole type species are supposedly less reactive and thus require more severe removal process conditions [26]. Both investigated feedstocks are dominated by pyridine-based aromatic nitrogen species. The DMO contains a significant amount of both types of nitrogen species, rendering it far more difficult to process. Findings of this research work will help to optimize the DMO ratio in hydrocracking feedstock blend.

\section{ACKNOWLEDGEMENT}

The authors gratefully thank Dr. Ryan Rogers of the National High Magnetic Field Laboratory, Florida State University, Florida, USA, and his group for providing the raw mass spectral data.

\section{REFERENCES}

1 Whitehurst D.D., Isoda T., Mochida I. (1998) Adv. Catal. 42, 345-471. 
2 Ng S., Zhu Y., Humphries A., Zheng L., Ding F., Gentzis T., Charland J.P., Yui S. (2002) Energ. Fuel. 16, 5, 1196-1208.

3 Rana M.S., Samano V., Ancheyta J., Diaz J.A.I. (2007) Fuel 86, 1216-1231.

4 U.S. Department of Energy (2007) Energy Information Administration

5 EPA U. (1999) Clean Air Act Tier 2.

6 European Parliament (2001) Directive 241 final.

7 Depauw G.A., Froment G.F. (1997) J. Chromatogr. A 761, 1 $2,231-247$

8 Schade T., Andersson J.T. (2006) J. Chromatogr. A 1117, 2, 206-213.

9 Marshall A.G., Hendrickson C.L., Klein G.C., Purcell J.M., Schaub T.M., Smith D.F., Stanford L.A., Rodgers R.P. (2006) 4th Upgrading and Refining of Heavy Oil, Bitumen, and Synthetic Crude Oil Conference, NCUT (eds.), Edmonton, Canada.

10 Choudhary T.V., Malandra J., Green J., Parrott S., Johnson B. (2006) Angew. Chem. Int. Edit. 45, 3299-3303.

11 Müller H., Schrader W., Andersson J.T. (2005) Anal. Chem. 77, 2536-2543.

12 Purcell J.M., Hendrickson C.L., Rodgers R.P., Marshall A.G. (2006) Anal. Chem. 78, 5906-5912.

13 Purcell J.M., Hendrickson C.L., Rodgers R.P., Marshall A.G. (2006) Anal. Chem. 78, 5906-5912.

14 Hakansson K., Chalmers M.J., Quinn J.P., McFarland M.A., Hendrickson C.L., Marshall A.G. (2003) Anal. Chem. 75, 32563262 .
15 Morrison M.E., Peries J.P., Morel F. (1994) Revue de l'IFP 49, $5,495-507$.

16 Process for Hydrocracker or Fluid Catalytic Cracker Feedstock Treatment, U.S. patent Application filed (2006).

17 Robb D.B., Covey T.R., Bruins A.P. (2000) Anal. Chem. 72, 15, 3653-3659.

18 Senko M.W., Canterbury J.D., Guan S., Marshall A.G. (2006) Rapid Commun. Mass Sp. 10, 1839-1844.

19 Müller H., Hajji A.A., Koseoglu O.R. (2007) Chemindex 2007 Proceeding - Extended Abstracts, March 26-28, 2007, Manama, Bahrain.

$20 \mathrm{Wu}$ Z., Rodgers R.P., Marshall A.G. (2004) Anal. Chem. 76, 9, 2511-2516.

$21 \mathrm{Fu}$ J., Klein G.C., Smith D.F., Kim S., Rodgers R.P., Hendrickson C.L., Marshall A.G. (2006) Energ. Fuel. 20, 3, $1235-1241$.

22 Laredo G.C., Leyva S., Alvarez R., Mares M.T., Castillo J., Cano J.L. (2002) Fuel 81, 10, 1341-1350.

23 Qian K., Rodgers R.P., Hendrickson C.L., Emmett M.R., Marshall A.G. (2001) Energ. Fuel. 15, 2, 492-498.

24 Cooper B.H., Knudsen K.G. (2006) in Practical Advances in Petroleum Processing, Hsu C.S., Robinson P.R. (eds.), Springer, ISBN 0387258116.

25 Usui K., Kidena K., Murata S., Nomura M., Trisunaryanti M. (2004) Fuel 83,14-15, 1899-1906.

26 Cooper B.H., Knudsen K.G. (2006) in Practical Advanvances in Petroleum Processing, Hsu C.S., Robinson P.R. (eds.), Springer, ISBN 0387258116.

Final manuscript received in July 2007 